\title{
Editorial: news and views from the RAFE
}

\author{
Stéphan Marette ${ }^{1} \cdot$ Ronan Le Velly ${ }^{2}$
}

Published online: 15 October 2020

(C) INRAE and Springer-Verlag France SAS, part of Springer Nature 2020

It is a great pleasure to write this editorial to present the new section in the Review of Agricultural, Food and Environmental Studies (RAFE) with the heading "News and Views" that should now appear regularly. This event also gives us the opportunity to take another look at the new editorial project, which has been implemented for 2 years now, leading to some remarkable results, notably in the recent publication of two special issues.

The "News and Views" section aims to gather two or three short articles which shed new light on a specific topic. Each paper offers a scientific point of view written by an expert in her/his field, for tackling overlooked problems, offering new insights, or underlining new ways of designing regulations and policies. For each further issue, a member of the RAFE editorial board will be in charge of selecting the authors coming from different horizons such as economics, sociology, history, geography, or political science.

The reason for creating this new section comes from major shifts that the world will most likely witness in the next 20 years. Indeed, agri-food systems face many new challenges, directly or indirectly related to the great fragility of the ecosystems supporting agriculture. This fragility leads us to strongly question production practices, consumption patterns, regulations, and policies all around the world. In this context, economic and sociological analyses should help identify uncertainties and controversies, understand the positions and strategies of key actors, design more sustainable organization, and assess the impacts of the implemented policies. The framework of this new section showcases short articles as a direct way to help debate problems and solutions. This first "News and Views" deals with one extremely hot topic: meat production and consumption. As explained below, the following three short articles emanate from original points of view, combining the fields of anthropology and economics.

Stéphan Marette

stephan.marette@agroparistech.fr

1 Université Paris-Saclay, INRAE, AgroParisTech, UMR Economie Publique, 78850 Grignon, France

2 UMR Innovation, Université de Montpellier, Cirad, INRAE, Institut Agro-Montpellier SupAgro, Montpellier, France 
This issue was preceded by two outstanding special issues. The first one dealing with "The Economics and Sociology of the Food-Health-Environment Nexus" and the second one focused on "The coexistence of agricultural and food models." These two special issues are a good illustration of the direction we want to give to the RAFE for the years to come. First, they show the benefit of crossing the economists and sociologists' perspectives. Scientific journals specialized in one discipline, or even a sub-discipline, often greatly benefit research in terms of deepening but also risk fragmenting the academic community. Even if the RAFE is proud to contribute to the most cutting-edge disciplinary debates, it also aims to be a space of exchange and confrontation between disciplines. Secondly, these two special issues also testify to the value of thinking simultaneously about agricultural, food, and environmental issues. Indeed, the choice of a common subject of investigation, namely, the Food-HealthEnvironment Nexus or the agricultural and food models, also makes it possible to go beyond the current division of labor that structures the academic world but also professional organizations or public policies. These two special issues appear to us to be illustrative of our desire to develop new research fronts.

Regarding the future, we hope that this new editorial project will contribute in succeeding to face these challenges ahead!

Publisher's note Springer Nature remains neutral with regard to jurisdictional claims in published maps and institutional affiliations. 